\title{
Mouth Progression GvHD
}

National Cancer Institute

\section{Source}

National Cancer Institute. Mouth Progression GVHD. NCI Thesaurus. Code C126727.

An NIH modified Oral Mucosa Rating Scale (OMRS) score that has increased by 2 or more points. 